\title{
PENDAMPINGAN DAN PELATIHAN PEMBUATAN SABUN CAIR DESA HUTAPUNGKUT JAE KECAMATAN KOTANOPAN MANDAILING NATAL UNTUK KEPERLUAN RUMAH TANGGA
}

Jureid 1

Siti Kholijah ${ }^{2}$

Muhlisah Lubis ${ }^{3 *}$

1,2,3 STAIN Mandailing Natal, Panyabungan, Indonesia

\author{
jureid@stain-madina.ac.id $\left.{ }^{1}\right)$ \\ sitikholijah@stain-madina.ac.id ${ }^{2}$ ) \\ muhlisahlubis@stain-madina.ac.id ${ }^{*}$ )
}

Kata Kunci: [Pelatihan,

Pendampingan, Sabun Cair, wirausaha]

\begin{abstract}
Abstrak: Peserta pelatihan yaitu pemuda desa Hutapungkut Jae adalah generasi yang perlu diberikan pendampingan untuk berwirausaha. Pelatihan pembuatan sabun cair ini bertujuan untuk melatih pemuda dan pelajar desa Hutapungkut Jae secara mandiri, metode yang digunakan adalah dengan koordinasi, pendampingan, penyuluhan dan pelatihan, kegiatan pengabdian masyarakat berhasil terlaksana sesuai dengan yang sudah direncanakan dan diprogramkan. Kegiatan pengabdian dari koordinasi, penyuluhan dan pelatihan mendapatkan sambutan yang baik dari Mitra Pengabdian yaitu Kepala Desa, Para Peserta Pemuda dan pelajar serta masyarakat setempat. Para peserta pelatihan mendapatkan keterampilan tambahan tentang pembuatan sabun mandi cair, serta termotivasi untuk berwirausaha dengan keterampilan tersebut.
\end{abstract}

Published by:

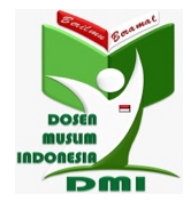

Copyright (C) 2021 The Author(s)

This article is licensed under CC BY 4.0 License

\section{(cc) BY}

https://dmi-journals.org/jai 


\section{Pendahuluan}

Pengabdian masyarakat adalah upaya mengabdikan diri didalam lingkungan masyarakat untuk mengembangkan berbagai hal yang dibutuhkan didalam masyarakat. Salah satu jenis pengabdian masyarakat yang sangat penting adalah upaya memberdayakan masyarakat dalam hal ekonomi yang dilakukan dengan jemput bola. Artinya tim pengabdi tidak menunggu panggilan tetapi berinisiatif sendiri untuk memberdayakan mereka, misalnya membuat suatu produk yang berguna bagi mereka (Jayatri \& Putri, 2020).

Pelatihan wirausaha sangat penting dilakukan kepada setiap orang tidak terkecuali siapapun. Pelatihan yang dilakukan sebagai upaya memberdayakan adalah indikator peningkatan kesejahteraan masyarakat (Susilawati et al., 2019). Saat masyarakat menjadi masyarakat terdidik, mempunyai hak-hak kepemilikan, dan dapat secara mandiri bekerja di luar rumah dengan penghasilan sendiri, maka ini adalah indikasi kesejahteraan masyarakat meningkat. Penanggulangan kemiskinan dapat dilakukan melalui masyarakat dan kelompok. Salah satu bukti adalah bahwa masyarakat dapat meningkatkan kesejateraan keluarganya dengan berusaha dan produktif dengan usahanya sendiri di rumah tangga.

Upaya memberdayakan mahasiswa dan pemuda-pemudi sebagai anggota masyarakat dan masih tergolong tenaga kerja produktif adalah sangat penting dilakukan, dengan tujuan untuk mengembangkan dan meningkatkan kemandirian dalam berusaha. Pemberdayaan juga sekaligus memperluas lapangan kerja guna meningkatkan penghasilan keluara masyarakat. Salah satu alternatif yang dipilih dalam rangka memberdayakan masyarakat adalah pelatihan dan penyuluhan pembuatan sabun cair. Sabun merupakan produk urgen yang tidak bisa terlepas dari kebutuhan rumah tangga masyarakat saat ini. Alat produksi yang digunakan untuk membuatnya cukup sederhana dan mudah diperoleh.

Sasaran utama dalam pelatihan sabun cair ini adalah para Pemuda dan Pelajar dan secara umum masyarakat yang berdomisili di Hutapungkut Jae boleh terlibat. Alternatif ini dipilih mengingat Pemuda dan Pelajar sangat membutuhkan pengetahuan, keahlian dan keterampilan yang dapat dijadikan bekal untuk berusaha dan berwirausaha. Harapan terbesar pemuda adalah menjadi generasi yang mandiri dan berkarya dengan keterampailan yang ada. Maka pelatihan ini sangat penting bagi mereka untuk menambah wawasan dan keterampilan dimaksud. Secara praktis yang terlibat dalam melaksanakan adalah pemuda itu sendiri dan yang mendampingi secara teknis.

Perubahan sosial yang diharapkan setelah terlaksananya pelatihan ini adalah pemuda dan pelajar dapat secara mandiri membuat sabun cair untuk memenuhi kebutuhan sabun cair rumah tangga mereka. Harapan terbesar adalah pemuda dan pelajar dapat secara mandiri berwirausaha untuk membantu meringankan ekonomi dan dan biaya pendidikannya. Hal ini adalah proses penting demi masa depan mereka, maka pengabdian ini layak didukung secara penuh oleh pemangku kepentingan desa Hutapungkut Jae Kecamatan Kotanopan. 
Target yang diharapkan dari pengabdian masyarakat ini adalah:

1. Pendampingan dan bimbingan pemuda dan pelajar Masyarakat Hutapungkut Jae dalam pelatihan pembuatan sabun cair.

2. Menambah wawasan keterampilan dan pengetahuan baru pemuda dan pelajar tentang cara pembuatan sabun cair dan mendapatkan bahanbahannya.

3. Barang berupa produk sabun cair yang dapat dimanfaatkan dan diperdagangkan oleh generasi muda masyarakat.

Target yang diharapkan dari pengabdian masyarakat ini adalah Laporan dan publikasi ilmiah yang menjadi referensi bagi masyarakat.

Pengabdian masyarakat berbasis pelatihan dalam pembuatan sabun cair sudah cukup banyak. Semua pengabdian tersebut berpengaruh positif terhadap kemajuan objek pengabdian. Misalnya pengabdian yang dilakukan oleh Widyasanti(Widyasanti et al., 2018) mengatakan bahwa pelatihan sabun cair ini dapat diterapkan dalam bentuk home industri yang dapat menambah penghasilan warga setempat.

Pelatihan pembuatan sabun cair yang dilakukan oleh Mahbubul Wathoni (Wathoni et al., 2019), yaitu pembuatan sabun cair dengan sabun batang dimasa pandemi. Proses pembuatan sabun cair dengan menggunakan sabun batang ini bisa dikatakan mudah untuk dilakukan. Dalam proses pembuatannya, tidak memerlukan banyak bahan yang digunakan. Saat pandemi, kita diharuskan untuk mencuci tangan dengan sabun untuk menjaga kesehatan. Manfaat dari mencuci tangan menggunakan sabun ialah agar terhindar dari berbagai macam kuman penyakit. Dengan membiasakan diri untuk mencuci tangan menggunakan sabun, kita akan menjaga kesehatan untuk diri sendiri dan orang lain.

Pangabdian dengan konsep pelatihan pembuatan sabun cair cuci tangan cair untuk mengatasi covid-19 oleh Mahkroji mengatakan pembuatan sabun cair cuci tangan ini sangat bermanfaat bagi peserta, efektifitasnya dalam mencegah covid 19 lebih bagus daripada handsanitizer (Makhroji et al., 2020)

\section{MetodePelaksanaan}

Pengabdian ini dilaksanakan di Desa Hutapungkut Jae Kecamatan Kotanopan Kabupaten Mandailing Natal bersama kelompok KKN STAIN Mandailing Natal sejak tanggal 23 Juli hingga 23 Agustus 2021. Namun pelaksanaan khusus terkait pengabdian pendampingan dan pelatihan pembuatan sabun cair adalah sejak tanggal 11 Agustus hingga 13 Agustus 2021 di kantor Kepala Desa Hutapungkut Jae. 

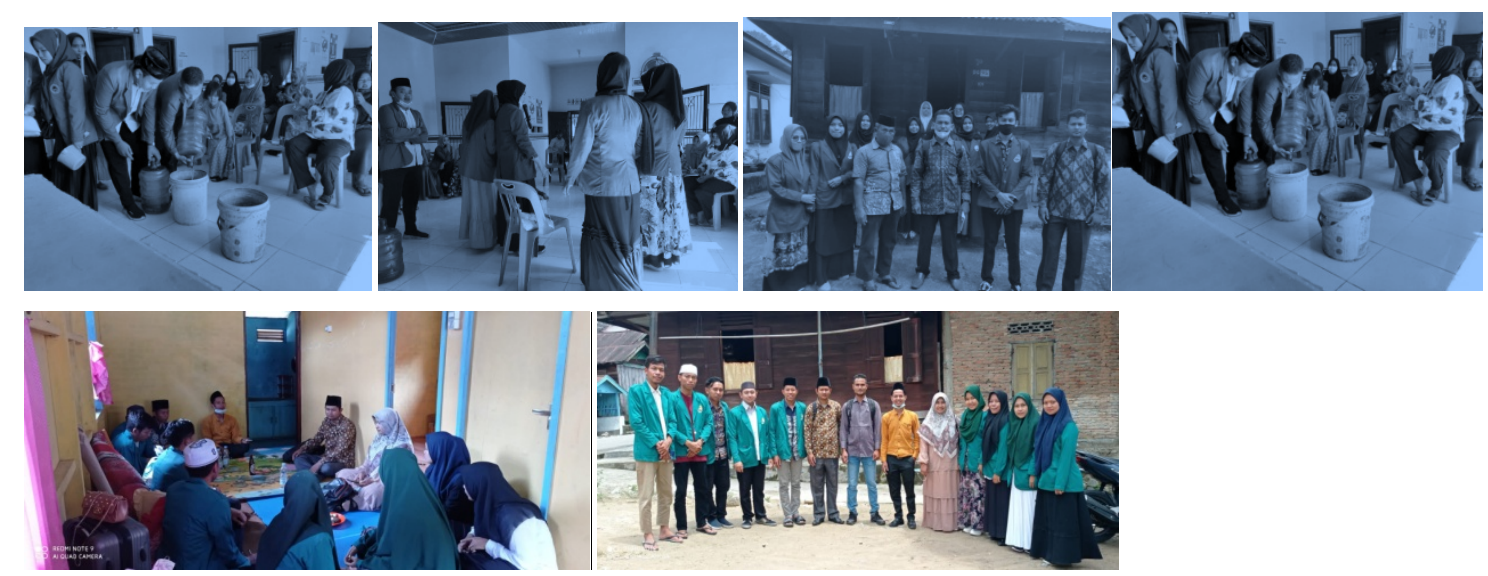

Gambar 1: Kegiatan Pelatihan Pembuatan sabun cair

Metode pelaksanaan pengabdian ini adalah sebagai berikut:

1. Koordinasi bersama mitra terkait sekaligus penyusunan jadwal kegiatan

2. Pendampingan dan Penyuluhan; materi penyuluhan menjelaskan tentang prinsip dasar cara pembuatan sabun cair, cara memperoleh bahan-bahan dan alat-alat yang digunakan dalam pembuatan dan teknik pengemasan.

3. Pelatihan; dalam pelatihan ini, terlebih dahulu diberikan demonstrasi contoh kepada peserta pelatihan dan kemudian dipraktikkan oleh peserta.

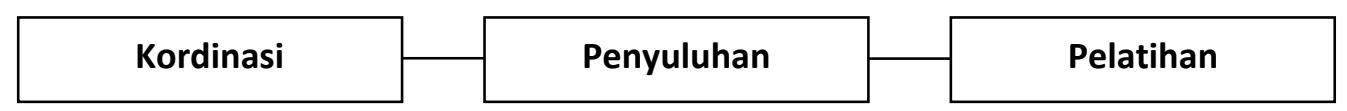

Gambar 2. Alur Metode Pelaksanaan Pengabdian

Tolak ukur atau indikator keberhasilan pada pelatihan ini adalah peserta tim pelatihan dapat membuat sabun cair secara mandiri setelah didemonstrasikan di hadapan mereka bersama, setelah itu peserta mempraktikkan sendiri sampai mahir dan sesuai harapan.

Setelah mereka dapat melakukan dan membuat sendiri sabun cair yang telah diajarkan, maka akan diadakan evaluasi membuat sendiri dirumah dan mengemas dengan kreasi sendiri sehingga dapat dimanfaatkan bersama.

\section{Hasil dan Pembahasan}

Pemakaian produk sabun cair di dalam rumah tangga adalah salah satu potensi yang sangat besar untuk pemuda dan pelajar yang melakukan pelatihan pembuatan sabun cair tersebut. Secara umum pengabdian berhasil dilakukan. Para peserta antusias, termotivasi dan ingin segera berwirausaha, dan harapan mereka sukses dalam memperaktikkan cara pembuatan sabun cair tersebut. Perlu dijelaskan bahwa pengabdian ini dilaksanakan di kantor Desa Hutapungkut Jae melibatkan pemuda setempat secara khusus dan masyarakat yang mau terlibat secara umum. 
Rangkaian kegiatan yang dilakukan adalah sebagai berikut:

\section{Kordinasi dengan pihak terkait}

Kordinasi tim pengabdian dengan pihak terkait dimaksud adalah dengan Kepala Desa, Sekretaris Desa, Ketua NNB (pemuda setempat), dan masyarakat secara umum. Pada pelaksanaan kegiatan ini tim pengabdian dan mitra membahas terkait alur kegiatan yang akan dilaksanakan, tempat dan waktu pelaksanaan penyuluhan dan pelatihan. Ada beberapa hal yang menjadi agenda yaitu sosialisasi kegiatan, waktu dan tempat pelaksanaan penyuluhan dan pelatihan pembuatan sabun cair.

\section{Persiapan penyuluhan dan pelatihan}

Penyuluhan dilakukan di kantor desa dengan pertimbangan lebih luas dan tidak ada orang yang lalu lalang yang dapat mengganggu jalannya kegiatan, serta berada dipusat desa.

Penyuluhan dilakukan dengan bentuk ceramah yang menjelaskan materi materi tentang metode dan cara pembuatan sabun cair dan penjelasan tentang bahan-bahan yang diperlukan dalam kegiatan tersebut. Adapun bahan-bahan yang digunakan adalah Alkali sebanyak $100 \mathrm{ml}$, Minyak zaitun, Minyak kelapa, Air dingin sebanyak $300 \mathrm{ml}$, Minyak esensial lainnya, Wadah sabun, Mangkuk dengan bahan stainless steel, Sendok pengaduk dengan bahan stainless steel, Thermometer bahan stainless steel, Pengukur bahan dasar stainless steel, Pipet, Kertas atau koran bekas, Handuk.

Bahan-bahan dalam pembuatan sabun cuci piring cair ini di beli dari toko kimia penjual bahan sabun di kota Medan. Bahan yang digunakan adalah Sodium Lauryl Sulfat (SLS) 500 gram, Texapon sebanyak 1000 gr, NaCl 50 gr, dan bahan aditif seperti parfum Aroma lemon 10 cc, Pewarna hijau 5 gr, anti bakteri, Pengawet dan Air 20 L.

Metode pembuatan dilakukan dengan cara $20 \mathrm{~L}$ air secara berturut-turut di campur dengan SLS 500 gram, 1000 gram texapon, dan bahan aditif lainnya kemudia di aduk sampai semua bahan tercampur. Kemudian pengemasan dilakukan setelah disimpan sampai 10 jam.

Kemudian setelah semua mengerti dan paham, dengan bimbingan tim pengabdian mempraktikkan pembuatan produk tersebut. Pelatihan diupayakan agar semua benar-benar paham dan mahir dalam mempraktikkannya. Pengabdian ini jelas telah menciptakan keahlian baru bagi pemuda dan peserta pelatihan lainnya, yang secara signifikan menumbuhkan jiwa dan semangat berusaha pada diri mereka masingmasing.

Sabun merupakan salah satu bagian dari kebutuhan mayarakat modern dengan frekuensi pembeliannya relatif tinggi.(Gustopo Setiadjit et al., 2018) Pemenuhan atas kebutuhan sabun tersebut sampai saat ini telah menjadikan terdapatnya peluang usaha untuk pemenuhannya. Pemberdayaan bagi masyarakat untuk mampu memproduksi sabun cair dirasa perlu dilakukan dengan mengingat pembuatan sabun cair relatif mudah untuk dipelajari, diproduksi dan dikembangkan. Diperlukan suatu bentuk kegiatan bagi masyarakat yang bersifat transfer pengetahuan dan pendampingan dari 
perguruan tinggi pada masyarakat yang menjadi sasaran program ini. Program pengabdian bagi masyarakat ini diimplementasikan pada Desa Hutapungkut Jae Kecamatan Kotanopan Kabupaten Mandailing Natal. Produksi yang berhasil dibuat oleh peserta pelatihan sejumlah 10 liter sabun cair, dan selanjutnya untuk dimasukkan ke dalam kemasan. Pada saat dilaksanakannya pelatihan peserta menginginkan produk yang telah dihasilkan tersebut untuk dibagikan pada warga RT masing- masing sebagai contoh sabun cair yang siap untuk dikonsumsi sendiri.

\section{Kesimpulan}

Berdasarkan hasil pelaksanaan kegiatan pengabdian, dapat disimpulkan bahwa kegiatan pengabdian masyarakat dapat terlaksana dengan baik sesuai dengan yang sudah direncanakan dan diprogramkan. Kegiatan pengabdian dari koordinasi, penyuluhan dan pelatihan mendapatkan sambutan yang baik dari Mitra Pengabdian yaitu Kepala Desa, Para Pserta Pemuda dan pelajar serta masyarakat setempat. Para peserta pelatihan mendapatkan keterampilan tambahan tentang pembuatan sabun cair, serta termotivasi untuk berwirausaha dengan keterampilan tersebut.

\section{Ucapan Terimakasih}

Penulis ucapkan terimakasih kepada kepala desa Hutapungkut Jae dan masyarakat desa, dan kelompok KKN STAIN Mandailing Natal yang telah mensukseskan pengabdian ini.

\section{Referensi}

Gustopo Setiadjit, D., Bagus Suardika, I., \& Utomo, A. (2018). Pelatihan Pembuatan Sabun Cair Di Desa Tunjungtirto Kecamatan Singosari Kabupaten Malang. JURNAL $\begin{array}{llll}\text { TEKNOLOGI DAN MANAJEMEN INDUSTRI, } & 4(1) .\end{array}$ https://doi.org/10.36040/jtmi.v4i1.195

Jayatri, F., \& Putri, D. Y. (2020). STRATEGI KOPERASI SYARIAH SIDOGIRI CABANG PEMBANTU YOSOWILANGUN DALAM MEMBERDAYAKAN MASYARAKAT EKONOMI LEMAH DI DESA YOSOWILANGUN LOR KECAMATAN YOSOWILANGUN KABUPATEN LUMAJANG. Economic and Education Journal (Ecoducation), 2(1). https://doi.org/10.33503/ecoducation.v2i1.737

Makhroji, M., Hasby, H., \& Nursamsu, N. (2020). Pelatihan Pembuatan Sabun Cuci Tangan Cair untuk Pencegahan Penularan COVID-19 di Desa Matang Teupah. JABDIPAMAS (Jurnal Pengabdian Kepada Masyarakat), 4(2). https://doi.org/10.30734/j-abdipamas.v4i2.1216

Susilawati, E., Sukmawati, I. K., Kusriani, R. H., \& Aligita, W. (2019). PELATIHAN TEKNOLOGI TEPAT GUNA PEMBUATAN SABUN CAIR PADA IBU-IBU PKK DI RW 9 DAN 17 DESA CIBIRU WETAN KECAMATAN CILEUNYI KABUPATEN BANDUNG. AMALIAH: JURNAL PENGABDIAN KEPADA MASYARAKAT, 3(1). https://doi.org/10.32696/ajpkm.v3i1.240 
Wathoni, M., Susanto, A., Kirana, A., \& Putri, D. (2019). Pemanfaatan Bahan Rumah Tangga dalam Pembuatan Sabun Cair dari Sabun Batang di Masa Pandemi. Seminar Nasional Pengabdian Masyarakat LPPM UMJ.

Widyasanti, A., Rosalinda, R., \& Putri, S. H. (2018). Upaya Pemberdayaan Masyarakat melalui Pembinaan Usaha Sabun Cair Handmade di Kelompok Rumah Insan Juara, Desa Cilengkrang, Kecamatan Cibiru, Kota Bandung. JURNAL PENGABDIAN KEPADA MASYARAKAT, 8(2). https://doi.org/10.30999/jpkm.v8i2.331 